\title{
Porokeratosis ptychotropica of the scrotum: dermoscopic evaluation of an atypical presentation*
}

\author{
Joana Cabete ${ }^{1}$ \\ André Lencastre ${ }^{1}$ \\ Alexandre João ${ }^{1}$
}

\author{
Ana Fidalgo ${ }^{1}$ \\ Filipa Diamantino ${ }^{1}$
}

\begin{abstract}
A bstract: Porokeratosis ptychotropica is a rare variant of porokeratosis that is classically located on the gluteal and perianal regions, seldom extending to the genitalia. The authors report an atypical presentation of porokeratosis ptychotropica and discuss the use of dermoscopy in evaluating this dermatosis. Dermoscopic findings, although not specific to this variant of porokeratosis, are helpful in the differential diagnosis of other genital disorders. Histopathology, through the visualization of multiple cornoid lamellae, prevails as the gold standard for the definite diagnosis of porokeratosis ptychotropica.
\end{abstract}

Keywords: Dermoscopy; Diagnosis, differential; Porokeratosis

\section{INTRODUTION}

Porokeratosis represents a heterogeneous group of keratinization disorders characterized by the histological finding of a cornoid lamella. ${ }^{1}$ Porokeratosis ptychotropica is a rare variant that is classically located on the gluteal, genital, and perianal regions. Clinical recognition can be challenging, and diagnosis is usually delayed. In the following case report, we describe the use of dermoscopy as a complement to clinical examination in the diagnosis of porokeratosis ptychotropica.

\section{CASE REPORT}

A34-year-old, otherwise healthy man presented with a mildly pruritic lesion located on the right scrotum, which he had had for two years. Friction with clothing was mentioned as an aggravating factor. Previous treatments with topical corticosteroids and antifungals failed to improve the condition. Physical examination revealed a single, annular, $1.5 \mathrm{~cm}-$ diameter plaque with a raised hyperkeratotic, ridgelike border on the scrotum (Figure 1A). The remaining observation was unremarkable. Differential clinical 

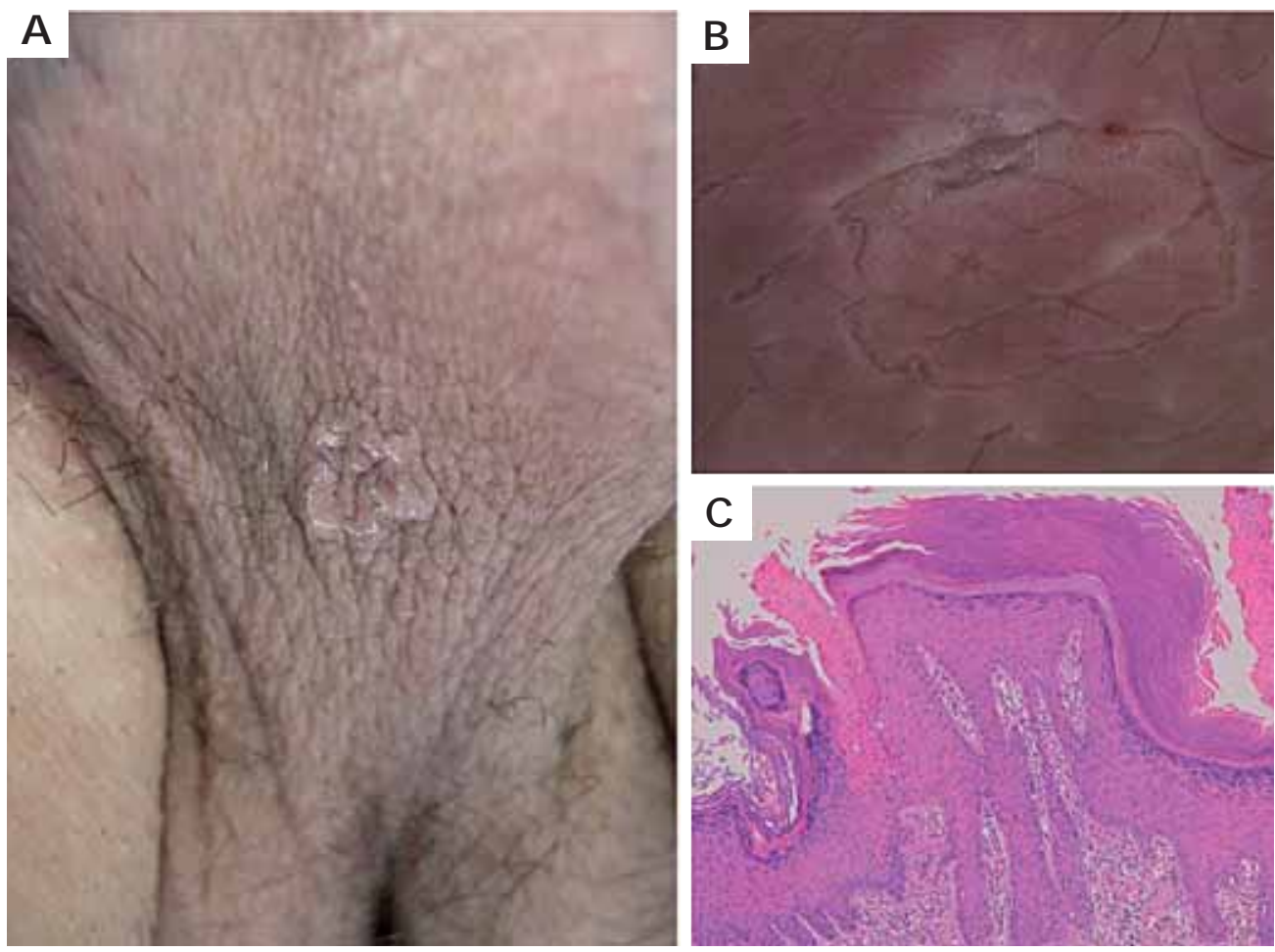

Figure 1: A - A single, annular plaque with hyperkeratotic, ridge-like border is observed in the right scrotum; B - Digital

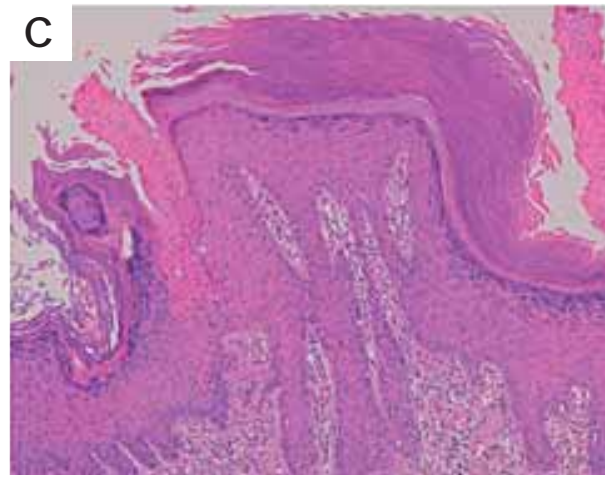
dermoscopy revealed a sharply demarcated annular lesion with a thick, peripheral light brown rim, limiting an erythematous nonatrophic centre with regular dotted vessels; C - Histopathology evidenced the presence of multiple cornoid lamellae (haematoxylin and eosin, original magnification $\mathrm{x} 100)$

diagnosis included porokeratosis, Bowen's disease, eczema, and genital psoriasis. Digital dermoscopy evidenced a sharply demarcated annular lesion with a thick, peripheral light brown rim, limiting an erythematous non-atrophic centre with regular dotted vessels (Figure 1B). Despite suggesting porokeratosis, a punch biopsy was done. Histopathological examination revealed hyperkeratosis, acanthosis, and the presence of multiple cornoid lamellae, consistent with the diagnosis of porokeratosis ptychotropica (Figure 1C). No amyloid deposition was observed.

Both cryotherapy and 5\% imiquimod cream (3 times a week for 16 weeks) were ineffective. Due to the small size of this single lesion, associated discomfort and unknown long-term malignancy potential, surgical excision was performed, further confirming the previous diagnosis. No recurrence has been observed.

\section{DISCUSSION}

Five primary, clinical variants of porokeratosis have been described: classic porokeratosis of Mibelli, disseminated superficial (actinic) porokeratosis, linear porokeratosis, punctate porokeratosis, and porokeratosis palmaris et plantaris disseminata. ${ }^{1}$ Porokeratosis ptychotropica is a rare variant described in 1995 by Lucker et al, and taken from the Greek words ptyche (fold) and trope (turning), in allusion to the pleated nature of this lesion. ${ }^{2}$ This feature is set by the distinct presence of multiple cornoid lamellae on histopathology. Of unknown cause, it appears to be more frequent in men, and it most commonly presents as symmetrical verrucous papules and plaques in the gluteal cleft and perianal region, hence the interchanging use of designations such as verrucous or hyperkeratotic porokeratosis. ${ }^{3}$ This classic presentation is often misdiagnosed as psoriasis, dermatophytosis, condyloma acuminata, or even as lichen simplex chronicus, among other inflammatory conditions.

Porokeratosis ptychotropica is rarely limited to male genitalia. ${ }^{4}$ Regardless of the localization, reported cases are consistently exuberant, perhaps as a consequence of delayed diagnosis. The case outlined, describing a single, non-verrucous lesion, may be regarded either as an initial presentation or a different clinical variant of porokeratosis ptychotropica. Also unique to this case is the dermoscopic description of porokeratosis ptychotropica, which, to our knowledge, had not previously been reported. As observed, this dermoscopic appearance is similar to other porokeratosis variants, with its distinct peripheral hyperkeratotic rim. ${ }^{5}$ Dermoscopy enables a quick assessment of several inflammatory and neoplastic diagnostic differentials.

Treatment has been disappointing in most 
reported cases. ${ }^{6}$ So far, complete remission has only been observed with dermabrasion and surgical treatment with the dermatome. ${ }^{7,8}$ This lent support to our pREFERENCES for surgical excision. Moreover, although no cases of malignancy have hitherto been reported following porokeratosis ptychotropica, neoplastic transformation cannot be ruled out completely in porokeratosis. ${ }^{9}$ Periodical clinical follow-up is prudent in persistent lesions.
In conclusion, porokeratosis ptychotropica is a non-venereal diagnosis to consider when evaluating genital lesions in men. Dermoscopic findings, although helpful, are not specific to this variant of porokeratosis, while histopathology, through the visualization of multiple cornoid lamellae, prevails as the gold standard for the definite diagnosis of porokeratosis ptychotropica.

\section{REFERENCES}

1. Requena L, Requena C, Cockerell CJ. Benign Epidermal Tumors and Proliferations. In: Bolognia JL, Jorizzo JL, Schaffer JV, editors. Bolognia, Dermatology. 3rd ed. Philadelphia, PA: Elsevier Saunders; 2012. p. 1801-3.

2. Lucker GP, Happle R, Steijlen PM. An unusual case of porokeratosis involving the natal cleft: porokeratosis ptychotropica? Br J Dermatol. 1995;132:150-1.

3. Takiguchi RH, White KP, White CR Jr, Simpson EL. Verrucous porokeratosis of the gluteal cleft (porokeratosis ptychotropica): a rare disorder easily misdiagnosed. J Cutan Pathol. 2010;37:802-7.

4. Wanat KA, Gormley RH, Bennett DD, Kovarik CL. Genitogluteal porokeratosis involving the scrotum: an unusual presentation of an uncommon disease. J Cutan Pathol. 2012;39:72-4.

5. Kittler H, Rosendahl C, Cameron A, Tschandl P. Dermatoscopy - An Algorithmic Method Based on Pattern Analysis. 1st ed. Vienna, Austria: Facultas Verlags- und Buchhandels AG; 2011.

6. Tallon B, Blumental G, Bhawan J. Porokeratosis ptychotropica: a lesser-known variant. Clin Exp Dermatol. 2009;34:e895-7.

7. Wallner JS, Fitzpatrick JE, Brice SL. Verrucous porokeratosis of Mibelli on the buttocks mimicking psoriasis. Cutis. 2003;72:391-3.

8. Scheiba N, Enk A, Proske S, Hartschuh W. Porokeratosis ptychotropica: successful treatment with the dermatome. Dermatol Surg. 2010;36:257-60.

9. Maubec E, Duvillard P, Margulis A, Bachollet B, Degois G, Avril MF. Common skin cancers in porokeratosis. Br J Dermatol. 2005;152:1389-91.
M AILING ADDRESS:

Joana Cabete

A lameda Santo A ntónio dos Capuchos

1169-050, Lisbon, Portugal.

E-mail: joanacabete@gmail.com

H ow to cite this article: Cabete J, Fidalgo A, Lencastre A, Diamantino F, João A. Porokeratosis ptychotropica of the scrotum: dermoscopic evaluation of an atypical presentation. An Bras Dermatol. 2015;90(3 Supl 1):S191-3 